\title{
Mechanical Properties and Microstructures of a Thin Plate of Nickel-Free Stainless Steel with Nitrogen Absorption Treatment
}

\author{
Daisuke Kuroda $^{1}$, Takao Hanawa ${ }^{1}$, Takaaki Hibaru ${ }^{2}$, Syuji Kuroda ${ }^{2}$ and Masaki Kobayashi ${ }^{2}$ \\ ${ }^{1}$ Biomaterials Center, National Institute for Materials Science, Tsukuba 305-0047, Japan \\ ${ }^{2}$ Steel Research Center, National Institute for Materials Science, Tsukuba 305-0047, Japan
}

\begin{abstract}
We have developed a new manufacturing process for nickel-free austenitic stainless steel. In combination with machining and a nitrogen absorption treatment, this process makes it possible to form small precise devices. However, the temperature for the nitrogen absorption, $1473 \mathrm{~K}$, was sufficiently high for grain growth, and coarsening was observed after nitrogen absorption. Therefore, a nitrogen absorption treatment which allows the retention of strength and ductility was performed with a grain refinement process before nitrogen absorption. In this study, we attempted the refinement of grains by thermo-mechanical treatment before nitrogen absorption treatment. The mechanical properties and microstructures of $\mathrm{Fe}-24 \mathrm{Cr}$ and $\mathrm{Fe}-24 \mathrm{Cr}-2 \mathrm{Mo}$ with fine grains before and after nitrogen absorption treatment were evaluated to understand the effects of grain refinement on nitrogen absorption. The austenintic phase was only obtained from the surface to a $0.1-\mathrm{mm}$ depth in Fe-24Cr and $\mathrm{Fe}-24 \mathrm{Cr}-2 \mathrm{Mo}$ with nitrogen absorption at $1473 \mathrm{~K}$ for $2.7 \mathrm{ks}$. The balance between strength and elongation in $\mathrm{Fe}-24 \mathrm{Cr}$ and $\mathrm{Fe}-24 \mathrm{Cr}-2 \mathrm{Mo}$ with nitrogen absorption at $1473 \mathrm{~K}$ for $2.7 \mathrm{ks}$ was better than that in conventional austenitic stainless steel. The values of ultimate tensile strength in both alloys with nitrogen absorption increased with the grain refinement process attempted in this study. The balance between strength and elongation in both alloys with nitrogen absorption over $2.7 \mathrm{ks}$ decreased because of grain growth. Therefore, the process described in this study can be used to manufacture small devices with a great deal of precision and parts with a maximum thickness or diameter of 0.2 mm in a short time. Grain refinement in a nickel-free austenitic stainless steel can increase the balance between the strength and elongation.
\end{abstract}

(Received January 14, 2003; Accepted May 15, 2003)

Keywords: nickel-free austenitic stainless steel, manufacturing process, nitrogen absorption, thin plate, mechanical properties

\section{Introduction}

Nickel-free austenitic stainless steels, such as $\quad \mathrm{Fe}-(19-23) \mathrm{Cr}-(21-24) \mathrm{Mn}-(0.5-1.5) \mathrm{Mo}-(0.85-1.1) \mathrm{N}$ (BioDure $\left.{ }^{\circledR} 108\right), \quad$ Fe-15Cr- $(10-15) \mathrm{Mn}-4 \mathrm{Mo}-0.9 \mathrm{~N}, \quad \mathrm{Fe}-$ $18 \mathrm{Cr}-18 \mathrm{Mn}-2 \mathrm{Mo}-0.9 \mathrm{~N}$, and $\mathrm{Fe}-(15-18) \mathrm{Cr}-(10-12) \mathrm{Mn}-$ (3-6) Mo- $-0.9 \mathrm{~N}$ in mass \% that have a high concentration of nitrogen and no nickel and show high strength and corrosion resistance, have been developed because nitrogen is an austenite former, as is nickel. ${ }^{1-4)}$ Nickel- and manganese-free austenitic stainless steel, $\mathrm{Fe}-23 \mathrm{Cr}-2 \mathrm{Mo}-1.5 \mathrm{~N}$ in mass $\%$, is also developed. ${ }^{5-7)}$ However, nickel-free austenitic stainless steels are difficult to work with for the production of small precise devices because the work hardening is large and the thermal conductivity is small in austenitic stainless steels. ${ }^{8)}$ In addition, the addition of nitrogen reduces the formability because it increases the brittleness of the austenitic phase. ${ }^{9}$ Therefore, the production of small precise devices with nickel-free austenitic stainless steel is expensive, and the dimensions of commercial products are limited.

Therefore, we have developed a new manufacturing process for nickel-free austenitic stainless steel. In combination with machining and a nitrogen absorption treatment, this process makes it possible to form small precise devices. Ingots of ferritic stainless steels, $\mathrm{Fe}-24 \mathrm{Cr}$ and $\mathrm{Fe}-24 \mathrm{Cr}-2 \mathrm{Mo}$ in mass\%, were worked to various dimensions for test specimens. Nitrogen was absorbed by the specimens in a furnace filled with nitrogen gas with a pressure of $101.3 \mathrm{kPa}$ at $1473 \mathrm{~K}$ to develop a simple and convenient manufacturing process of nickel-free austenitic stainless steels. Changes in the mechanical properties of both alloys with nitrogen absorption treatment are discussed on the basis of the resultant microstructure. Ferritic $\mathrm{Fe}-24 \mathrm{Cr}$ and $\mathrm{Fe}-24 \mathrm{Cr}-2 \mathrm{Mo}$ were austenitized with nitrogen absorption to a 2-mm depth from the surface. The hardness, ultimate tensile strength, $0.2 \%$ proof stress, and elongation to fracture increased, and the reduction of area decreased in $\mathrm{Fe}-24 \mathrm{Cr}$ and $\mathrm{Fe}-24 \mathrm{Cr}-$ $2 \mathrm{Mo}$ by austenitization due to nitrogen absorption. The ultimate tensile strength and $0.2 \%$ proof stress of these alloys with nitrogen absorption for $129.6 \mathrm{ks}$ were much larger than those of $316 \mathrm{~L}$ steel, while the elongation to fracture and reduction of area were much smaller than those of $316 \mathrm{~L}$ steel. Therefore, small devices and parts with a maximum thickness or diameter of $4 \mathrm{~mm}$ were manufactured with this process in this study.

However, the temperature for nitrogen absorption, $1473 \mathrm{~K}$, is sufficiently high for grain growth, and coarsening is observed after nitrogen absorption. Nitrogen absorption is performed with a diffusion of nitrogen through the grain boundary, that is, a diffusion from the surface to the grain boundary and from the grain boundary to the inside grain, indicating that coarsening decreases the rate of nitrogen absorption. In addition, the coarsening causes a decrease in the ultimate tensile strength and elongation to fracture. Therefore, a nitrogen absorption treatment that allows the retention of strength and ductility is performed with a grain refinement process before nitrogen absorption.

Grain refinement is a fundamental technique to control the microstructure of metallic materials, and a fine grain generates high strength and ductility. Thermo-mechanical treatments utilizing phase transformation and recrystallization, rapid cooling solidification, and mechanical alloying are effective techniques to obtain fine grains. ${ }^{10)}$ Among the above processes, thermo-mechanical treatment is the most popular because it is applied to various shapes and dimensions. To obtain fine grains with recrystallization, as many crystal nuclei as possible must be generated during forging. This is achieved by the increase of nucleation sites and the 
generation of many dislocations under a cold forging process.

In this study, we attempted the refinement of grains by thermo-mechanical treatment before nitrogen absorption treatment. The mechanical properties and microstructures of $\mathrm{Fe}-24 \mathrm{Cr}$ and $\mathrm{Fe}-24 \mathrm{Cr}-2 \mathrm{Mo}$ with fine grains generated by hot forging and cold forging before and after nitrogen absorption treatment were evaluated to understand the effects of grain refinement on nitrogen absorption.

\section{Experimental Procedure}

\subsection{Specimen preparation}

Ingots with $3.5 \mathrm{~kg}$ of $\mathrm{Fe}-24 \mathrm{Cr}$ and $\mathrm{Fe}-24 \mathrm{Cr}-2 \mathrm{Mo}$ in mass $\%$ were prepared by a vacuum high-frequency induction melting process. Table 1 shows the chemical compositions of the ingots of $\mathrm{Fe}-24 \mathrm{Cr}$ and $\mathrm{Fe}-24 \mathrm{Cr}-2 \mathrm{Mo}$. The ingots were then cut into two equal parts. A schematic diagram of the forging process is shown in Fig. 1. Hot forging, followed by $25 \%$ cold forging, was conducted in the previous study. ${ }^{11)}$ In this study, $95 \%$ cold forging was conducted after hot forging to obtain finer grains than in the previous study. ${ }^{11)} \mathrm{A}$ thin plate $(0.2 \mathrm{~mm}$ in thickness) was obtained through hot and cold forging. Specimens for the tensile test $(0.2 \mathrm{~mm}$ in thickness, $5 \mathrm{~mm}$ in width, and $10 \mathrm{~mm}$ in gage length) were prepared from the thin plates of $\mathrm{Fe}-24 \mathrm{Cr}$ and $\mathrm{Fe}-24 \mathrm{Cr}-2 \mathrm{Mo}$ with machining using a milling machine. The tensile axis was the same as the rolling direction in specimens for the tensile test.

\subsection{Nitrogen absorption}

Specimens for the tensile test of $\mathrm{Fe}-24 \mathrm{Cr}$ and $\mathrm{Fe}-24 \mathrm{Cr}-$ 2Mo were polished with \#600 SiC paper in water and then ultrasonically rinsed in acetone for $300 \mathrm{~s}$. After polishing, the specimens were separately fixed to a 304 steel reticular stage. The area for nitrogen absorption in the specimens did not contact the stage. The stage with the specimen was inserted into the nitrogen absorption furnace as shown in Fig. 2. The pressure of the inside of the furnace was reduced to $2 \mathrm{~Pa}$, and nitrogen gas $(<99.99 \%)$ was introduced and continuously blown into the furnace to maintain a pressure of $101.3 \mathrm{kPa}$. The temperature of the furnace was increased from ambient to $1473 \mathrm{~K}$ at a rate of $0.08 \mathrm{~K} \mathrm{~s}^{-1}$ and kept for a specific time for $1.8 \mathrm{ks}, 2.7 \mathrm{ks}, 3.6 \mathrm{ks}, 4.5 \mathrm{ks}$, and $5.4 \mathrm{ks}$. Immediately after heating, the specimen was quenched into a water bath. The scale on tensile test specimens generated was not removed after nitrogen absorption.

\subsection{Microstructural examination}

Gripped parts of tensile test specimens were employed for microstructural observation with an optical microscope. Specimens for microstructural examination were finally polished with \#600 SiC paper and buffed. After etching with a Villela reagent, the microstructure was observed with an optical microscope. Phases of specimens for the tensile test with and without nitrogen absorption were identified using Xray diffraction analysis (XRD) with $\mathrm{CuK} \alpha$ radiation $(40 \mathrm{kV}$ and $300 \mathrm{~mA}$ ).

\subsection{Hardness test}

Gripped parts of tensile test specimens with and without nitrogen absorption were employed for a hardness test with a micro Vickers hardness tester to estimate the changes in hardness with nitrogen absorption. Specimens for the hardness test were finally polished with \#600 SiC paper and buffed. In addition, changes in hardness that were the result of heating and not nitrogen absorption were investigated by heating under the same temperature and time as the nitrogen absorption treatment in an argon atmosphere. At least, three measurements were carried out under the same conditions, and the mean values were calculated.

\subsection{Tensile test}

The tensile test was performed in air using an Instron-type tensile test machine with a capacity of $10 \mathrm{kN}$. The crosshead

Table 1 Chemical compositions of $\mathrm{Fe}-24 \mathrm{Cr}$ and $\mathrm{Fe}-24 \mathrm{Cr}-2 \mathrm{Mo}$ (mass\%).

\begin{tabular}{|c|c|c|c|c|c|c|c|c|c|c|}
\hline & $\mathrm{C}$ & $\mathrm{Mn}$ & $\mathrm{P}$ & S & $\mathrm{Ni}$ & $\mathrm{Cr}$ & Mo & $\mathrm{O}$ & $\mathrm{N}$ & $\mathrm{Fe}$ \\
\hline $\mathrm{Fe}-24 \mathrm{Cr}$ & 0.002 & - & $<0.002$ & 0.0002 & $<0.01$ & 25.70 & - & 0.018 & $<0.001$ & Bal. \\
\hline $\mathrm{Fe}-24 \mathrm{Cr}-2 \mathrm{Mo}$ & 0.002 & - & $<0.002$ & 0.0002 & $<0.01$ & 25.80 & 2.04 & 0.016 & $<0.001$ & Bal. \\
\hline
\end{tabular}

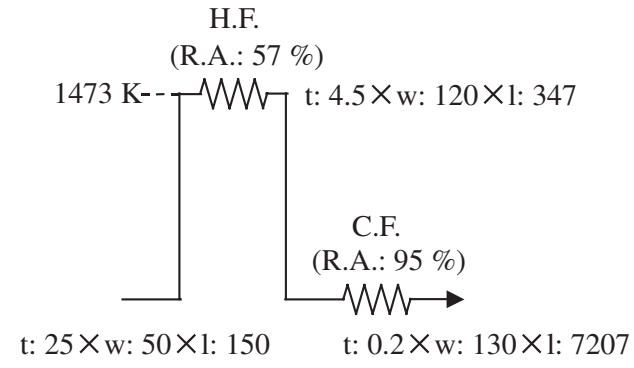

$(\mathrm{mm})$

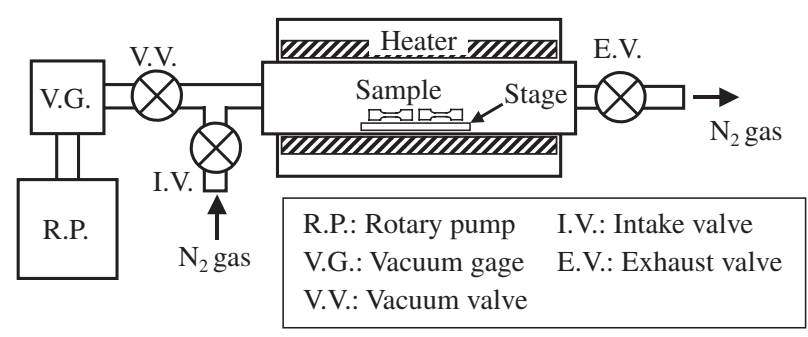

Fig. 2 Schematic diagram of the nitrogen absorption system.

Fig. 1 Schematic diagram of the forging process of a thin plate. H.F.: hot forging, C.F.: cold forging, R.A.: reduction of area, $t$ : thickness, $w$ : width, and $l$ : length. 
speed was $8.33 \times 10^{-6} \mathrm{~m} \mathrm{~s}^{-1}$. Ultimate tensile strength, $0.2 \%$ proof stress, elongation to fracture, and reduction of area were estimated throughout the tensile test. At least, five measurements were carried out under the same conditions, and the mean values were calculated. The fractured surfaces of $\mathrm{Fe}-24 \mathrm{Cr}$ and $\mathrm{Fe}-24 \mathrm{Cr}-2 \mathrm{Mo}$ specimens were observed with a scanning electron microscope (SEM).

\section{Results and Discussion}

\subsection{Changes in microstructures by nitrogen absorption}

Figure 3 shows the XRD profiles of $\mathrm{Fe}-24 \mathrm{Cr}$ and $\mathrm{Fe}-$ $24 \mathrm{Cr}-2 \mathrm{Mo}$ with and without nitrogen absorption. Only the diffraction pattern of ferrite ( $\alpha$ phase) was observed from both $\mathrm{Fe}-24 \mathrm{Cr}$ and $\mathrm{Fe}-24 \mathrm{Cr}-2 \mathrm{Mo}$ without nitrogen absorption, indicating that the structure consisted of only $\alpha$ phase. $\mathrm{XRD}$ profiles from $\mathrm{Fe}-24 \mathrm{Cr}$ and $\mathrm{Fe}-24 \mathrm{Cr}-2 \mathrm{Mo}$ with nitrogen absorption for $1.8 \mathrm{ks}$ showed peaks originating from both $\alpha$ phase and austenite ( $\gamma$ phase), indicating that the structure consisted of both $\alpha$ and $\gamma$ phases. On the other hand, those for $2.7 \mathrm{ks}$ showed only peaks originating from the $\gamma$ phase, indicating that the structure was completely transformed to the $\gamma$ phase. Therefore, thin plates of $\mathrm{Fe}-24 \mathrm{Cr}$ and $\mathrm{Fe}-24 \mathrm{Cr}-$ $2 \mathrm{Mo}$ with a thickness of $0.2 \mathrm{~mm}$ are completely austenitized with nitrogen absorption treatment over $2.7 \mathrm{ks}$. On the other hand, round bars of both alloys with a diameter of $4 \mathrm{~mm}$ were completely austenitized with nitrogen absorption treatment over $43.2 \mathrm{ks}^{11)}$ Nitrogen absorption in stainless steel proceeds with diffusion through the grain boundary and diffusion from the grain boundary to the inside of the grain. ${ }^{12)}$ However, nitrogen absorption in stainless steel with a coarse grain mainly proceeds by the lattice diffusion. The thickness of the specimens in this study $(0.2 \mathrm{~mm})$ was smaller than that in the previous study $(4 \mathrm{~mm}) .{ }^{11)}$ Therefore, thin plates of both alloys in this study were completely austenitized with nitrogen absorption in short time.

Using XRD, neither $\mathrm{CrN}$ nor $\mathrm{Cr}_{2} \mathrm{~N}$ was identified in any specimen with nitrogen absorption, indicating that no nitride was formed in $\mathrm{Fe}-24 \mathrm{Cr}$ and $\mathrm{Fe}-24 \mathrm{Cr}-2 \mathrm{Mo}$ with nitrogen absorption.

Figures 4 and 5 show the microstructures of $\mathrm{Fe}-24 \mathrm{Cr}$ and $\mathrm{Fe}-24 \mathrm{Cr}-2 \mathrm{Mo}$ with nitrogen absorption treatment for each time. $\mathrm{Fe}-24 \mathrm{Cr}$ and $\mathrm{Fe}-24 \mathrm{Cr}-2 \mathrm{Mo}$ before nitrogen absorption consisted of a fine $\alpha$ phase expanded along the rolling direction. The $\alpha$ phase was completely transformed to a $\gamma$ phase after 1.8-ks nitrogen absorption. Fine grains in $\mathrm{Fe}-$ $24 \mathrm{Cr}$ and $\mathrm{Fe}-24 \mathrm{Cr}-2 \mathrm{Mo}$ were grown and coarsened with the nitrogen absorption treatment. The grains were the largest with 5.4-ks nitrogen absorption (Figs. 4(f) and 5(f)). The mean grain sizes of both alloys after 5.4-ks nitrogen absorption were $125 \mu \mathrm{m}$ and $80 \mu \mathrm{m}$, respectively. On the other hand, those of both alloys after 129.6-ks nitrogen absorption in the previous study were $750 \mu \mathrm{m}$ and $604 \mu \mathrm{m}$, respectively. ${ }^{11)}$ The grain size in this study was smaller than that in the previous study, ${ }^{11)}$ indicating that grains in both alloys were refined with the grain refinement process attempted in this study. The grains in $\mathrm{Fe}-24 \mathrm{Cr}-2 \mathrm{Mo}$ were smaller than those in $\mathrm{Fe}-24 \mathrm{Cr}$ independently of the nitrogen absorption time.

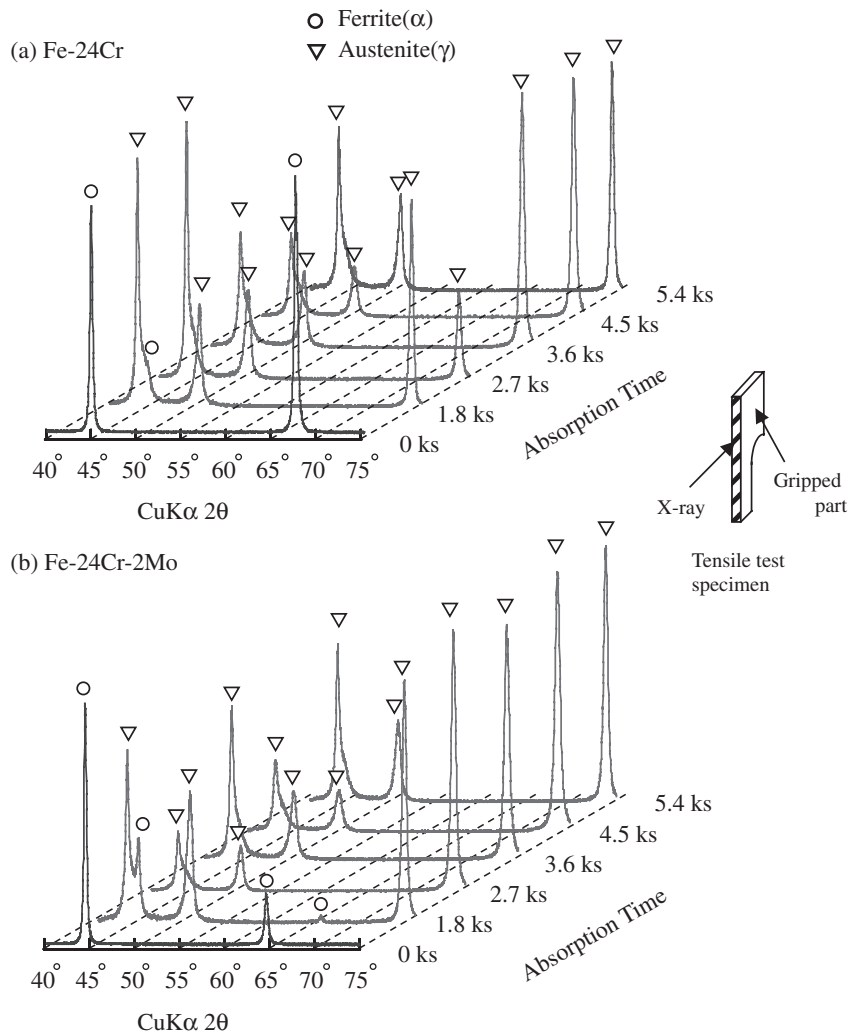

Fig. 3 X-ray diffraction patterns of (a) $\mathrm{Fe}-24 \mathrm{Cr}$ and (b) $\mathrm{Fe}-24 \mathrm{Cr}-2 \mathrm{Mo}$ with and without nitrogen absorption.

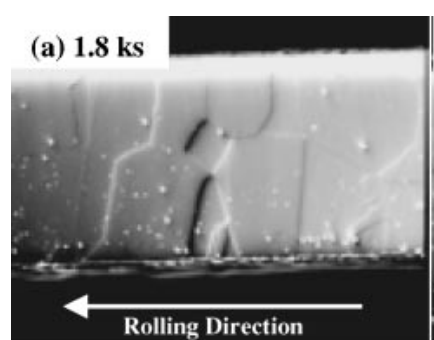

(d) $4.5 \mathrm{ks}$

(b) $2.7 \mathrm{ks}$

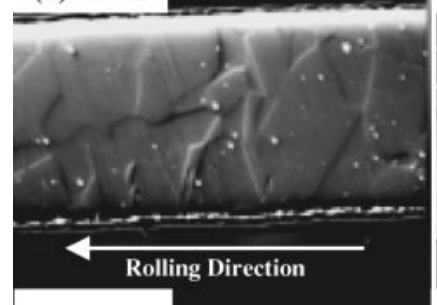

(c) $3.6 \mathrm{ks}$
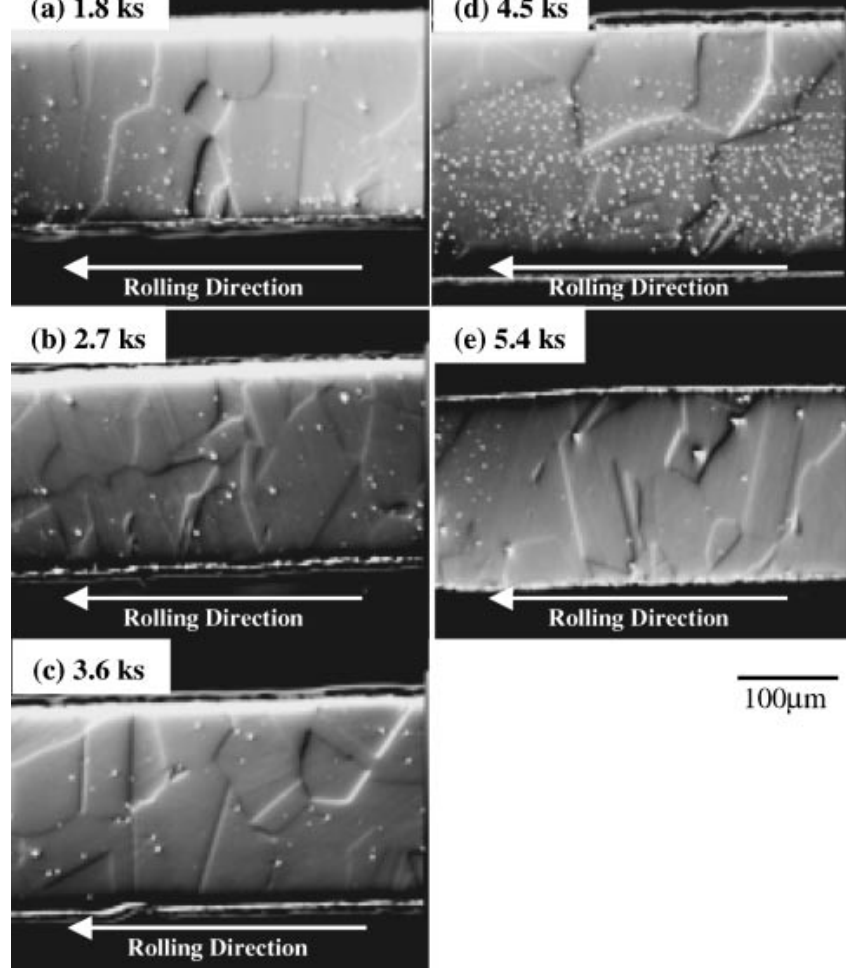

(e) $5.4 \mathrm{ks}$

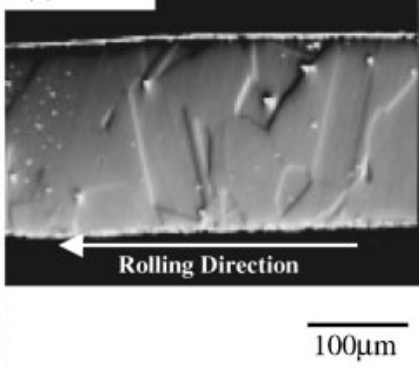

Fig. 4 Optical microstructures of $\mathrm{Fe}-24 \mathrm{Cr}$ with nitrogen absorption treatment. 


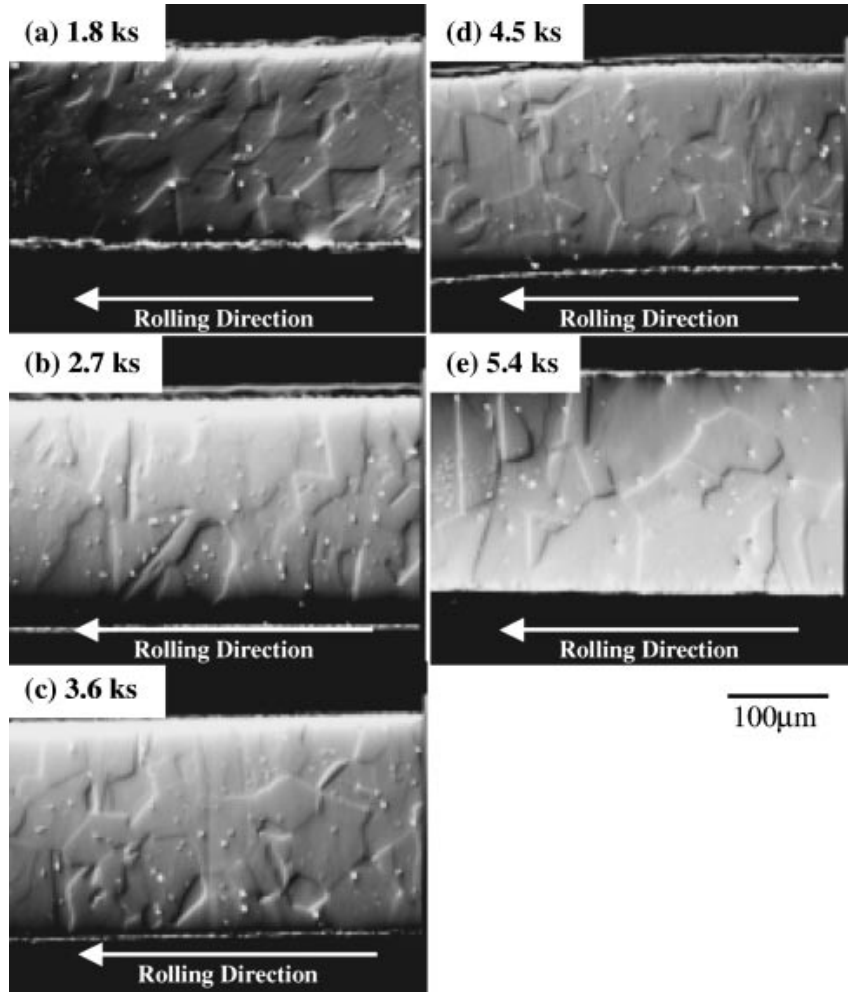

Fig. 5 Optical microstructures of $\mathrm{Fe}-24 \mathrm{Cr}-2 \mathrm{Mo}$ with nitrogen absorption treatment.

\subsection{Changes in micro Vickers hardness by nitrogen absorption}

Figure 6 shows the changes in micro Vickers hardness of $\mathrm{Fe}-24 \mathrm{Cr}$ and $\mathrm{Fe}-24 \mathrm{Cr}-2 \mathrm{Mo}$ with and without nitrogen absorption treatment. For comparison, those with heating in an argon atmosphere are also shown. Although the micro Vickers hardness of these alloys after annealing was 140 150 , that of thin plates of alloys after $95 \%$ cold forging was

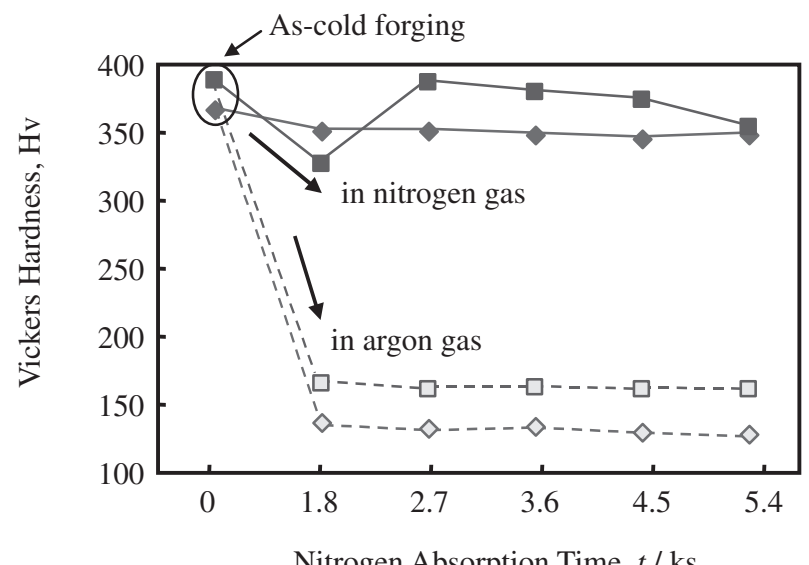

Nitrogen Absorption Time, $t$ / ks

$\begin{array}{|cc|}\begin{array}{c}\text { in nitrogen gas } \\ \mathrm{Fe}-24 \mathrm{Cr}\end{array} & --\diamond--\mathrm{Fe}-24 \mathrm{Cr} \\ \mathrm{Fe}-24 \mathrm{Cr}-2 \mathrm{Mo} & --\square--\mathrm{Fe}-24 \mathrm{Cr}-2 \mathrm{Mo}\end{array}$

Fig. 6 Comparison of the micro Vickers hardness of $\mathrm{Fe}-24 \mathrm{Cr}$ and $\mathrm{Fe}-$ $24 \mathrm{Cr}-2 \mathrm{Mo}$ with and without nitrogen absorption and $\mathrm{Fe}-24 \mathrm{Cr}$ and $\mathrm{Fe}-$ $24 \mathrm{Cr}-2 \mathrm{Mo}$ heated at $1473 \mathrm{~K}$ in an argon atmosphere.
360 in $\mathrm{Fe}-24 \mathrm{Cr}$ and 390 in $\mathrm{Fe}-24 \mathrm{Cr}-2 \mathrm{Mo}$ because of work hardening. The hardness of these alloys decreased after 1.8ks nitrogen absorption because of the release of residual stress. The hardness of $\mathrm{Fe}-24 \mathrm{Cr}$ was almost constant after a longer treatment, while that of $\mathrm{Fe}-24 \mathrm{Cr}-2 \mathrm{Mo}$ showed the maximum value $(H v=388)$ at $2.7-\mathrm{ks}$ nitrogen absorption and decreased after $2.7 \mathrm{ks}$. The hardness of thin plates of $\mathrm{Fe}-$ $24 \mathrm{Cr}$ and $\mathrm{Fe}-24 \mathrm{Cr}-2 \mathrm{Mo}$ with nitrogen absorption for over $2.7 \mathrm{ks}$ was the same as that of a round bar of either alloy with nitrogen absorption for $126.9 \mathrm{ks}$. The microstructures of both alloys with nitrogen absorption for 129.6 ks showed only a $\gamma$ phase. Therefore, the $\gamma$ phase was also obtained by nitrogen absorption for $2.7 \mathrm{ks}$ in thin plates of both alloys. On the other hand, the hardness decreased in an argon atmosphere with heating for $1.8 \mathrm{ks}$, and the value was maintained when the duration of the heating was extended. The hardness of Fe$24 \mathrm{Cr}-2 \mathrm{Mo}$ was larger than that of $\mathrm{Fe}-24 \mathrm{Cr}$ with nitrogen absorption treatment over $2.7 \mathrm{ks}$. The magnitude of solidsolution strengthening by nitrogen in $\mathrm{Fe}-24 \mathrm{Cr}-2 \mathrm{Mo}$ was larger than that in $\mathrm{Fe}-24 \mathrm{Cr}$ because nitrogen solubility in $\gamma$ phase increased with increasing chromium and molybdenum contents. ${ }^{13)}$ In addition, the difference in hardness between these alloys is also caused by the difference in microstructure, which is shown in Figs. 4 and 5.

According to the results on hardness and microstructure, the mechanical strength of the thin plate in this study is expected to be larger than that of the round bar previously studied. ${ }^{11)}$

\subsection{Changes in mechanical properties by nitrogen absorption}

Ultimate tensile strength, $0.2 \%$ proof stress, elongation to fracture, and reduction of area of $\mathrm{Fe}-24 \mathrm{Cr}$ and $\mathrm{Fe}-24 \mathrm{Cr}-2 \mathrm{Mo}$ with and without nitrogen absorption treatment are shown in Fig. 7. Figure 7 contains the results in $316 \mathrm{~L}$ steel for comparison. The tensile strength and elongation to fracture of $\mathrm{Fe}-24 \mathrm{Cr}-2 \mathrm{Mo}$ (969 MPa and 5\%, respectively) were larger than those of $\mathrm{Fe}-24 \mathrm{Cr}(797 \mathrm{MPa}$ and $3 \%$, respectively) before nitrogen absorption. The tensile strength and $0.2 \%$ proof stress of both alloys with nitrogen absorption were larger than those of $316 \mathrm{~L}$ steel, while the elongation to fracture and reduction of area in both alloys were smaller than those of $316 \mathrm{~L}$ steel. $\mathrm{Fe}-24 \mathrm{Cr}$ and $\mathrm{Fe}-24 \mathrm{Cr}-2 \mathrm{Mo}$ with nitrogen absorption for $2.7 \mathrm{ks}$ showed maximum ultimate tensile strength, $1032 \mathrm{MPa}$ and $1167 \mathrm{MPa}$, respectively. On the other hand, $\mathrm{Fe}-24 \mathrm{Cr}$ and $\mathrm{Fe}-24 \mathrm{Cr}-2 \mathrm{Mo}$ with nitrogen absorption for $129.6 \mathrm{ks}$ in the previous study ${ }^{11}$ ) showed maximum ultimate tensile strength, $823 \mathrm{MPa}$ and $982 \mathrm{MPa}$, respectively. ${ }^{11)}$ The values of ultimate tensile strength in both alloys with nitrogen absorption increased with the grain refinement process attempted in this study. The tensile strength of these alloys decreased with nitrogen absorption over $2.7 \mathrm{ks}$, a phenomenon caused by grain growth with the treatment times shown in Figs. 4 and 5. This indicates that the gage region of the tensile test specimen is deformed uniformly rather than locally. This uniform deformation under a large stress is caused by a significant magnitude of work hardening. The gradient of plastic deformation on the stress-strain curves is calculated as follows: 

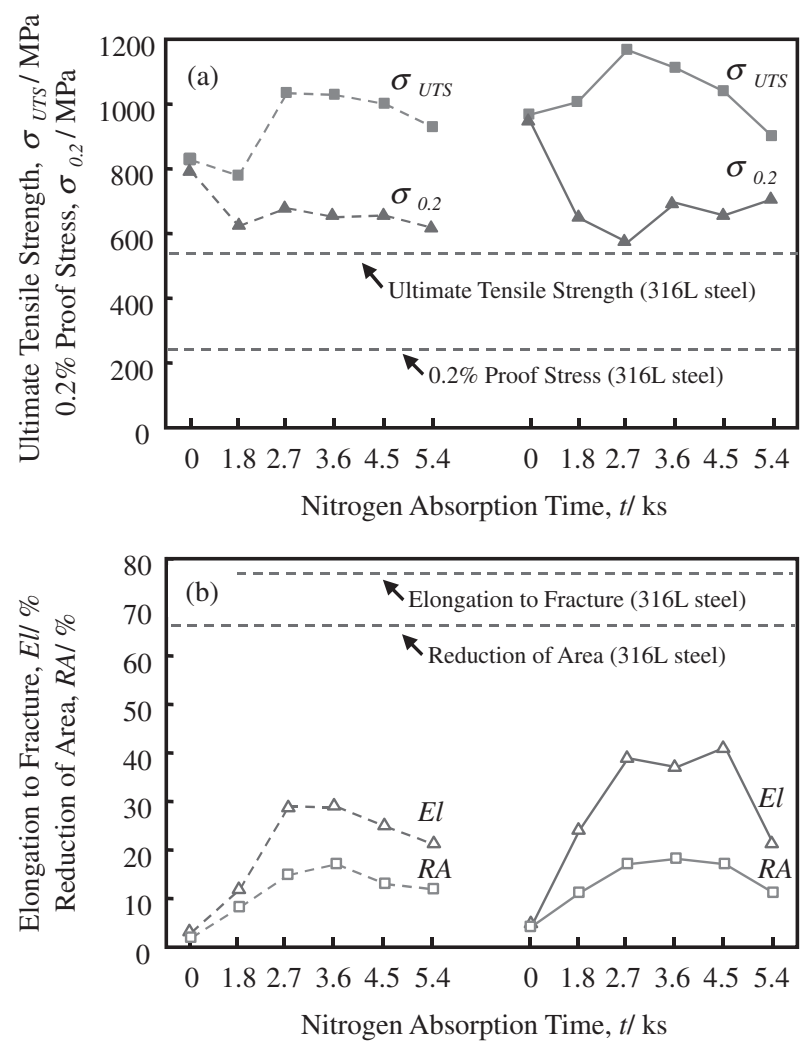

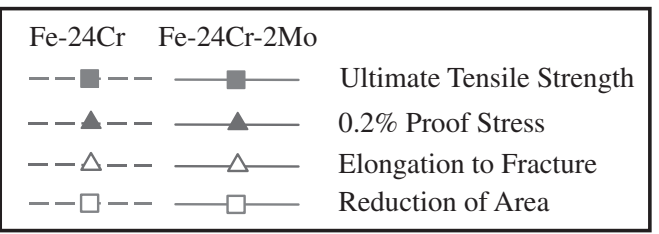

Fig. 7 (a) Ultimate tensile strength and $0.2 \%$ proof stress and (b) elongation to fracture and reduction of area of $\mathrm{Fe}-24 \mathrm{Cr}$ and $\mathrm{Fe}-$ $24 \mathrm{Cr}-2 \mathrm{Mo}$ with and without nitrogen absorption.

\section{((Ultimate tensile strength $)-(0.2 \%$ proof stress $)) /$ strain}

The calculated values for $\mathrm{Fe}-24 \mathrm{Cr}$ and $\mathrm{Fe}-24 \mathrm{Cr}-2 \mathrm{Mo}$ with nitrogen absorption for $2.7 \mathrm{ks}$ are $1.2 \mathrm{GPa}$ and $1.5 \mathrm{GPa}$, respectively. The value in $316 \mathrm{~L}$ steel obtained in the previous study $^{11)}$ is $0.5 \mathrm{GPa}$, and the values in $\mathrm{Fe}-24 \mathrm{Cr}$ and $\mathrm{Fe}-24 \mathrm{Cr}-$ $2 \mathrm{Mo}$ were twice larger than the value in $316 \mathrm{~L}$ steel.

Therefore, the work hardening in nitrogen-absorbed alloys is accelerated with a solution of nitrogen, which caused high ductility. No martensite ( $\alpha^{\prime}$ phase) was observed at the fractured surface nor was it identified using XRD, indicating that no stress-induced martensitic transformation in specimens with nitrogen absorption occurred.

Figure 8 shows the relation between ultimate tensile strength and elongation to fracture of $\mathrm{Fe}-24 \mathrm{Cr}$ and $\mathrm{Fe}-24 \mathrm{Cr}-$ $2 \mathrm{Mo}$ with and without nitrogen absorption. The figure also contains the data on a round bar of each alloy with nitrogen absorption for $129.6 \mathrm{ks}$ and $316 \mathrm{~L}$ steel previously reported. ${ }^{11)}$ The best balance between strength and elongation was given by $2.7-\mathrm{ks}$ nitrogen absorption in both $\mathrm{Fe}-24 \mathrm{Cr}$ and $\mathrm{Fe}-24 \mathrm{Cr}-$ $2 \mathrm{Mo}$, and the balance was better than that in the round bar specimens and 316L steel shown in the previous study. ${ }^{11)}$

Scanning microphotographs of fractured surfaces of $\mathrm{Fe}-$ $24 \mathrm{Cr}$ and $\mathrm{Fe}-24 \mathrm{Cr}-2 \mathrm{Mo}$ with and without nitrogen absorp-

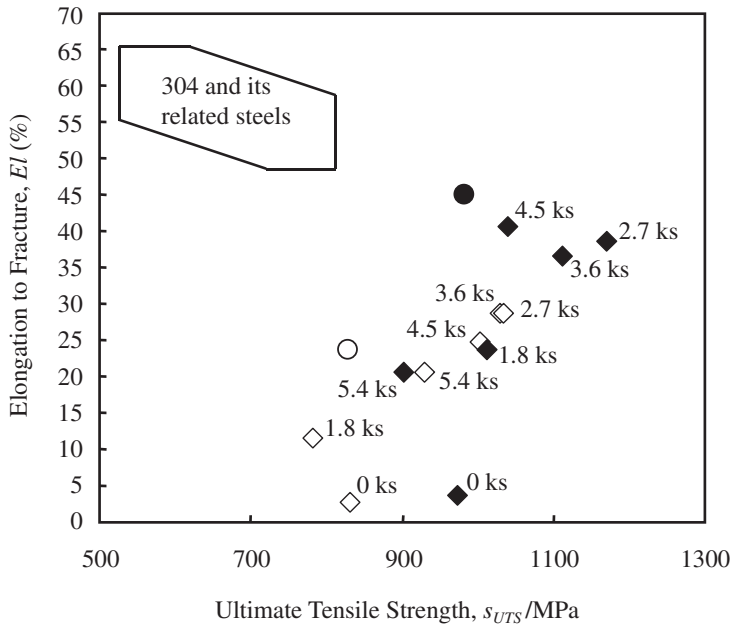

$\begin{array}{|lll|}\diamond \mathrm{Fe}-24 \mathrm{Cr} \text { (Plate) } & \bigcirc & \mathrm{Fe}-24 \mathrm{Cr}\left(\text { Round Bar) }{ }^{11)}\right. \\ \diamond \mathrm{Fe}-24 \mathrm{Cr}-2 \mathrm{Mo} \text { (Plate) } & \bigcirc & \mathrm{Fe}-24 \mathrm{Cr}-2 \mathrm{Mo}(\text { Round Bar) } \\ \end{array}$

Fig. 8 Ultimate tensile strength and elongation to fracture of $\mathrm{Fe}-24 \mathrm{Cr}$ and $\mathrm{Fe}-24 \mathrm{Cr}-2 \mathrm{Mo}$ with and without nitrogen absorption and of conventional austenitic stainless steels.

tion treatment are shown in Figs. 9 and 10. Specimens without nitrogen absorption show a ductile fracture surface containing dimples (Figs. 9(a) and 10(a)). Fe-24Cr and Fe24Cr-2Mo after 2.7-ks nitrogen absorption specimens show good ductility (Fig. 7(b)), while specimens with nitrogen absorption show a brittle fracture surface containing both intergranular and transgranular fracture surfaces. In each alloy, the roughness and intergranular-fractured surface area on the fracture surface increased with nitrogen absorption treatment time. The addition of nitrogen reduces the formability because it increases the brittleness of the $\gamma$ phases. ${ }^{9)}$ In addition, the grain boundary cracks generate during cold rolling in a highly nitrogen contained $(0.9$ mass $\%) \mathrm{Fe}-\mathrm{Cr}-$ $\mathrm{Mn}-\mathrm{N}$ steel. ${ }^{14)}$ Over 0.9 mass $\%$ nitrogen can be absorbed by $\mathrm{Fe}-24 \mathrm{Cr}$ and $\mathrm{Fe}-24 \mathrm{Cr}-2 \mathrm{Mo}$ with nitrogen absorption treatment. ${ }^{11)}$ Therefore, the brittle fractures observed in both alloys with nitrogen absorption were caused by brittleness of the $\gamma$ phase. In both cases, coarsening with treatment time was observed. The grains in $\mathrm{Fe}-24 \mathrm{Cr}-2 \mathrm{Mo}$ with nitrogen absorption were finer than those in $\mathrm{Fe}-24 \mathrm{Cr}$. This is in good agreement with the results of microstructural observation as shown in Figs. 4 and 5. The decreases in the ultimate tensile strength and elongation to fracture of the alloys with 5.4-ks nitrogen absorption were caused by coarsening.

The mechanical strength of $\mathrm{Fe}-24 \mathrm{Cr}$ and $\mathrm{Fe}-24 \mathrm{Cr}-2 \mathrm{Mo}$ is governed by the refinement of grains, according to the results of microstructural observations, tensile test, and observation of fractured surface.

\section{Conclusions}

The $\gamma$ phase was only obtained from the surface to a 0.1 $\mathrm{mm}$ depth in $\mathrm{Fe}-24 \mathrm{Cr}$ and $\mathrm{Fe}-24 \mathrm{Cr}-2 \mathrm{Mo}$ with nitrogen absorption at $1473 \mathrm{~K}$ for $2.7 \mathrm{ks}$. The balance between strength and elongation in $\mathrm{Fe}-24 \mathrm{Cr}$ and $\mathrm{Fe}-24 \mathrm{Cr}-2 \mathrm{Mo}$ with nitrogen absorption at $1473 \mathrm{~K}$ for $2.7 \mathrm{ks}$ was better than that in conventional austenitic stainless steel. The values of ultimate 

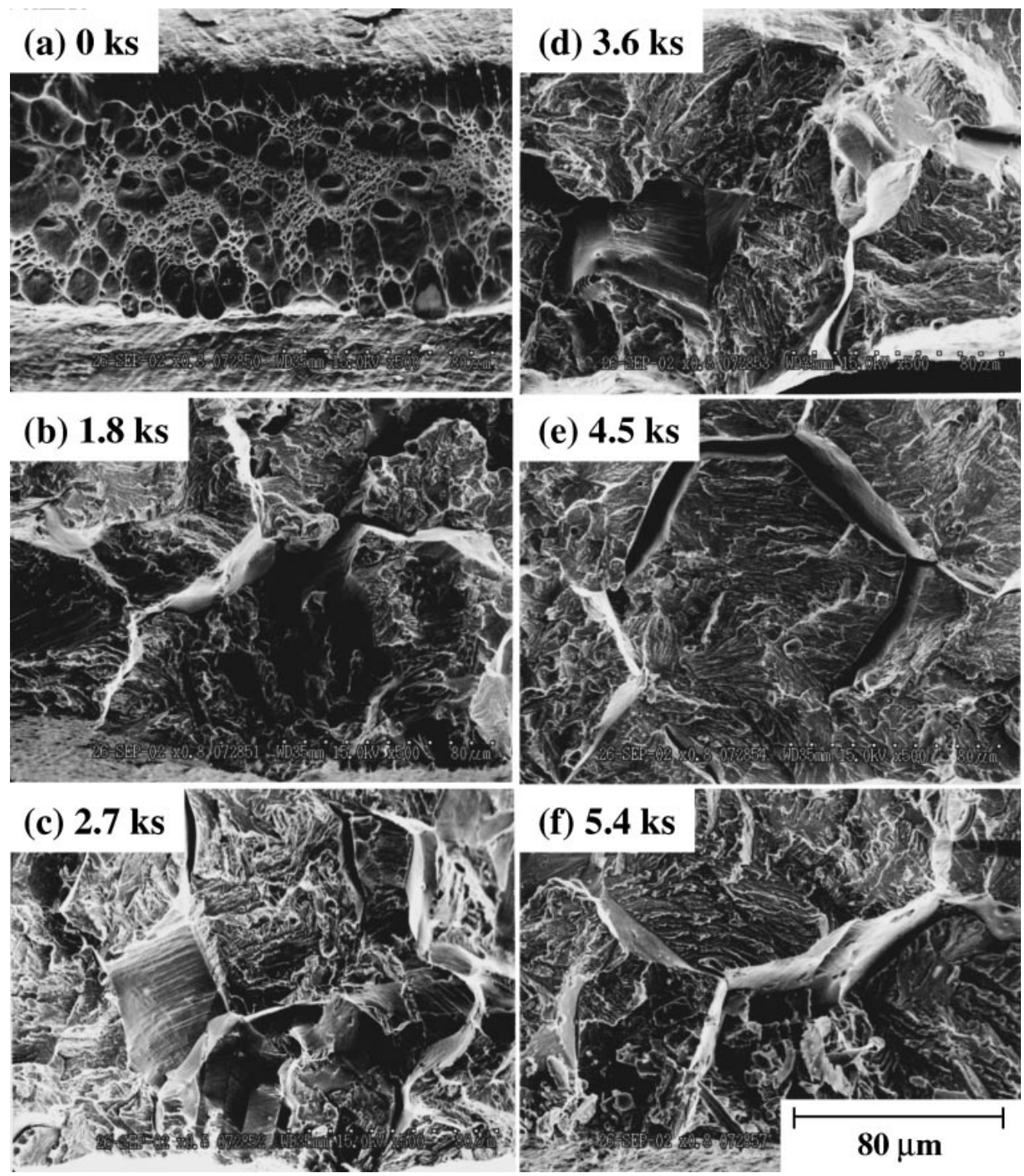

Fig. 9 Scanning electron micrographs of fractured surfaces of $\mathrm{Fe}-24 \mathrm{Cr}$ with nitrogen absorption for (a) $0 \mathrm{ks}$, (b) $1.8 \mathrm{ks}$, (c) $2.7 \mathrm{ks}$, (d) $3.6 \mathrm{ks}$, (e) $4.5 \mathrm{ks}$, and (f) $5.4 \mathrm{ks}$. 

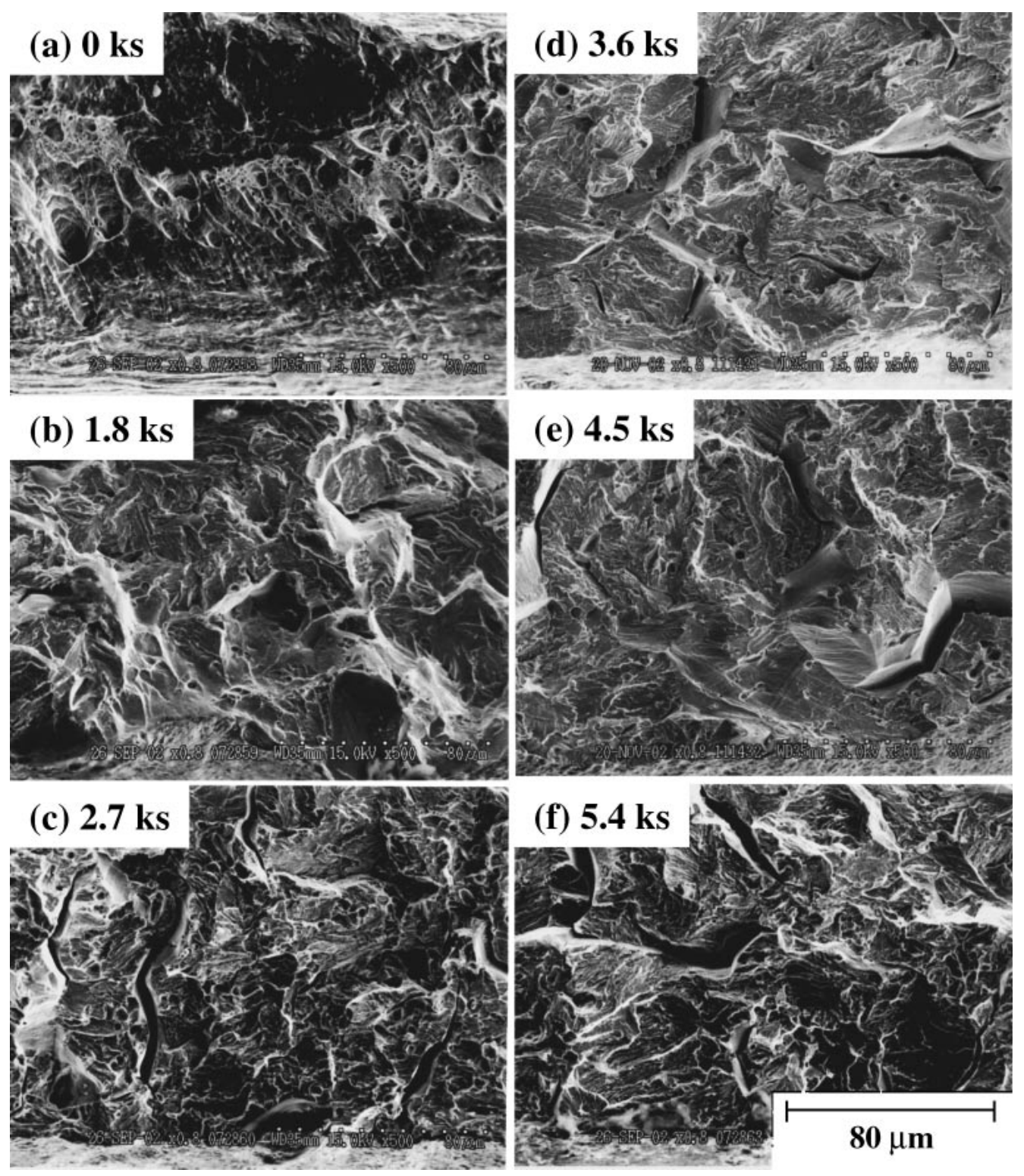

Fig. 10 Scanning electron micrographs of fractured surfaces of $\mathrm{Fe}-24 \mathrm{Cr}-2 \mathrm{Mo}$ with nitrogen absorption for (a) $0 \mathrm{ks}$, (b) $1.8 \mathrm{ks}$, (c) $2.7 \mathrm{ks}$, (d) $3.6 \mathrm{ks}$, (e) $4.5 \mathrm{ks}$, and (f) $5.4 \mathrm{ks}$.

tensile strength in both alloys with nitrogen absorption increased with the grain refinement process attempted in this study. The balance between strength and elongation in the both alloys with nitrogen absorption over $2.7 \mathrm{ks}$ decreased because of grain growth. Therefore, the process described in this study can be used to manufacture small precise devices and parts with a maximum thickness or diameter of $0.2 \mathrm{~mm}$ in a short time. Grain refinement in a nickel-free austenitic stainless steel can increase the balance between the strength and elongation.

\section{Acknowledgements}

We would like to thank Mr. Hironori Kawasaki for his valuable support during the experiments.

\section{REFERENCES}

1) Y. Katada, M. Sagara, S. Iwasaki, K. Sakuraya and T. Kodama: Cur.
Adv. Mater. Process. 13 (2000) 116.

2) Y. Katada, H. Uno, M. Sagara, M. Ogawa, H. Baba, S. Iwasaki, K. Sakuraya, K. Hiroka, T. Kodama and C. Shiga: J. Mater. Process. Technol. 117 (2001) CD-ROM Section B1.

3) R. C. Gebeau and R. S. Brown: Adv. Mater. Process. 159 (2001) 46-48.

4) J. Menzel, W. Kirschner and G. Stein: ISIJ Int. 36 (1996) 893-900.

5) P. J. Uggowitzer, R. Magdowski and M. O. Speidel: ISIJ Int. 36 (1996) 901-908.

6) D. Kuroda, S. Hiromoto, T. Hanawa and Y. Katada: Mater. Trans. 43 (2002) 3100-3104.

7) D. Kuroda, T. Hanawa, S. Hiromoto, Y. Katada and K. Asami: Mater. Trans. 43 (2002) 3093-3099.

8) Japanese Stainless Steel Association: Sutenresukou Binrann, (Nikankogyoshinbunsya, Tokyo, 1995) pp. 491-492.

9) G. Stein and J. Menzel: Stahl Eisen 112 (1992) 47-52.

10) M. Maki: J. Jpn. Soc. Heat Treat. 40 (2000) 287-291.

11) D. Kuroda, T. Hanawa, T. Hibaru, S. Kuroda, M. Kobayashi and T. Kobayashi: Mater. Trans. 44 (2003) 414-420.

12) K. Kataoka, T. Tsuchiyama, H. Goto and S. Takaki: J. Jpn. Soc. Powder Metallurgy 46 (1999) 922-926.

13) F. Ishii and T. Fuwa: Tetsu-to-Hagané 68 (1982) 1560-1568.

14) N. Akdut and J. Foct: ISIJ Int. 36 (1996) 883-892. 